\title{
A transient current based micro-grid connected power system protection scheme using wavelet approach
}

\author{
S.Chandra Shekar ${ }^{1}$, G.Ravi Kumar ${ }^{2}$, S.V.N.L Lalitha ${ }^{3}$ \\ ${ }^{1,3}$ Department of Electrical and Electronics Engineering, Anurag Engineering College, India \\ ${ }^{2}$ Department of Electrical and Electronics Engineering, Bapatla Engineering College, India
}

\begin{tabular}{l}
\hline Article Info \\
\hline Article history: \\
Received Feb 18, 2018 \\
Revised Sep 9, 2018 \\
Accepted Sep 29, 2018 \\
\hline
\end{tabular}

Keywords:

Fault inception angle Micro-grid protection scheme Wavelet based multi-resolution analysis

\begin{abstract}
Micro-grids comprise Distributed Energy Resources (DER's) with low voltage distribution networks having controllable loads those can operate with different voltage levels are connected to the micro-grid and operated in grid mode or islanding mode in a coordinated way of control. DER's provides clear environment-economical benefits for society and consumer utilities. But their development poses great technical challenges mainly protection of main and micro grid. Protection scheme must have to respond to both the main grid and micro-grid faults. If the fault is occurs on main grid, the response must isolate the DER's from the main grid rapidly to protect the system loads. If the fault ocuurs within the micro-grid, the protection scheme must coordinate and isolates the least priority possible part of the grid to eliminate the fault. In order to deal with the bidirectional energy flow due to large numbers of micro sources new protection schemes are required. The system is simulated using MATLAB Wavelet Tool box and Wavelet based Multi-resolution Analysis is considered. Wavelet based Multiresolution Analysis is used for detection, discrimination and location of faults on transmission network. This paper is discussed a transient current based micro-grid connected power system protection scheme using Wavelet Approach described on wavelet detailed-coefficients of Mother Biorthogonal 1.5 wavelet. The proposed algorithm is tested in micro-grid connected power systems environment and proved for the detection, discrimination and location of faults which is almost independent of fault impedance, fault inception angle (FIA) and fault distance of feeder line.
\end{abstract}

Copyright (C) 2019 Institute of Advanced Engineering and Science. All rights reserved.

\section{Corresponding Author:}

S.V.N.L Lalitha,

Department of Electrical and Electronics Engineering,

Koneru Lakshmaih Education Foundation,

Vaddeswaram, AP, India.

Email: lalitha@kluniversity.in

\section{INTRODUCTION}

The increase in demand of energy worldwide requires the use of various electric power sources combined by a common grid for making an efficient electrical energy system. The DER's are becoming more popular compared with conventional integreting system. In many cases DER's generate power with different technologies through micro sources like Solar Photovoltaic and wind energy during the decade. The concept of micro-grid has emerged as an incredible way to integrate micro sources in electric power network. Its benefits mainly, it supplies local power, reduces grid cost due to few Megawatts, reduces operation costs, system losses and peak time load problems such that increasing reliability [1]. Micro-grids have considerable advantages the issue of its protection. In conventional network, power flows from HV level to LV level and during the fault the shortcircuit current decrease as distance increase. The concept of modern micro-grid has been changed and power flow is bidirectional. Some of main important protection [2] issues are: shortcircuit 
power, current level of fault and its direction, device discrimination, uneven tripping, protection blinding, etc. There are some main issues like determination of the time at the time of islanding from the main grid in response to abnormalities. Conventional methods of detection and discrimination of faults are becoming unreliable due to increasing size of the network and inefficient algorithms. Setting of threshold levels based on current or voltage amplitudes are frequently prone to mistakes such that a tripping decision may be become wrong judgement for small disturbances in the system and sometimes give the maloperation of tripping without any fault in the system. The necessacity of well coordinated and reliably protection scheme is needed so that it can be tripped reliably during the occurance of a fault within it. The research proposed here is done for the detection, discrimination and location of faults on DER's integration in transmission network using Wavelet based Multi-resolution Analysis using Wavelet transform. For this purpose the 3- $\Phi$ current signals of the local terminal are decomposed with Mother Biorthogonal 1.5 wavelet, over a $1 / 2$ cycle window and analysed the hidden information of fault situation in the network. The detection and discrimination of fault can be done within a $1 / 2$ cycle using detail-coefficients of current signals. A new algorithm is described which is independent of fault impedance fault location and FIA. The proposed protection scheme is proven to be fast, accurate and reliable for various types of faults on Micro-grid Connected Power System.

\section{TECHNICAL CHALLENGES IN MICRO-GRID PROTECTION}

The micro-grid has number of challenges mainly protection, controlling and dispatching perspective [7]. But due to their specific mode of characteristics and operation, this protection scheme has to deal with new technical challenges [8]. The major challenges are protection scheme for micro-grid must respond to main grid and micro-grid faults. In case one, the protection scheme has to separate the micro-grid from main grid rapidly to protect micro-grid loads. In case two, the protection scheme has to separate the least priority part of micro-grid rapidly to clear the fault in the system. Some issues relate to protection of micro-grids and distributed grids with a large interconnection of DER's have been discussed in recent publications. They are related to a number of installed units in the micro-grid and availability of sufficient level of shortcircuit current in the islanding mode of micro-grid. The shortcircuit current calculations of radial feeders with DER's and observed that shortcircuit currents which are used in overcurrent protection relays depend on a connection point and a feed-in power from DER's. In order to get high performance and better AC power quality of the converters, it is worthful to control directly the phase angle and magnitude of 3- $\Phi$ supply currents [3]. In addition, controllable islanding of different size and content can be formed due to faults in the main grid or within micro-grid.

In such case relay loss of co-ordination may occur and standard overcurrent protection with one trip setting group may become unsatisfactory, therefore, it is essential to ensure that trip settings to be chosen for overcurrent protection relays taken into account with respect to grid topology, change in location, quantity and type of power generation. Otherwise, maloperation or failure of operation may occur when it is required. This paper is discussed a novel adaptive micro-grid protection scheme $[4,5]$ concept by using advanced type communication system, real time measurements and data collection from offline shortcircuit analysis [6]. This concept is based on an adaptation of protective relay trip settings with regard to a micro-grid topology, generation and variation in loads. A segmentation of micro-grid must supported by micro-sources and load controllers. In these circumstances problems relates selectivity and sensitivity of protection scheme may arise.

\section{WAVELET ANALYSIS}

Wavelet Transform is a linear transformation like a Fourier-Transform, with only one important difference: for a given signal it permits time localization of different frequency components. So, it is a mathematical analysis used in signal analysis. Wavelet analysis is particularly effective where the signals to be analyzed have discontinuities or transients, e.g., voltage or current signls after the fault. In wavelet transform, the analyzing functions are called Wavelets. The wavelets adjust their time width to their frequency in which, high frequency wavelets are narrow and low frequency ones are wider. Wavelet transform is a tool that cuts the data/functions/operators into different components of frequency, and then analyse resolution matched with each component to its scale [9].

Wavelets decomposes signals of transients in the form of series of wavelet components having each of time domain signals that covers a specific octave frequency band having detailed information. These wavelet components are useful for detecting and discriminating the sources of surges. Hence, it is feasible and practically proved for analyzing signals of disturbances and transients [10]. 
Wavelet transform plays great importance in power sector since a decade, because it is well suited for the analysis of transient signals than other transforms approaches. Power transmission network protection is done with a set of basic functions called Wavelets used to decompose the signal in various frequencies, which are obtained from a Mother Biorthogonal 1.5 wavelet by dilation and translation. So that incidence and amplitude of each frequency can be found accurately [11]. A given function $\mathrm{f}(\mathrm{t})$, its continuous wavelet transform be calculated as follows:

$$
W T(a, b)=\frac{1}{\sqrt{a}} \int x(t) g\left(\frac{t-b}{a}\right) d t
$$

Where ' $a$ ' is scaling (dilation) \& ' $b$ ' is translation (time-shift) constants and ' $\mathrm{g}$ ' is the function of wavelet for simplicity which may not be real as assumed in the equation [12]. The selection of mother-wavelet is based on type of signal. In the following section a novel method of Wavelet based Multi-resolution Analysis of transient currents associated with the fault is discussed for detection and discrimination of faults [13].

\section{SYSTEM MODELLING AND RESULT ANALYSIS}

Solar Photovoltaic and wind energy have emerged energy sources interconnected to a point of common coupling to the main grid with an aim to to generate power that will improve reliability in power supply against the load demand. Both Solar Photovoltaic and wind energy are variable in nature and depends on climatic changes. Fortunately, the problems can be moderately overcome by integrating the DER's to form a hybrid Micro-grid system, power generation of one source overcome the limitation of the other power generation [14]. The DER's connected to Micro-grid are allocated to compensate the shortage power as per load demands. However, the interfacing of Micro-grid with these DER's makes number of power quality and islanding issues which must be detected, analyzed and mitigated effectively. Solar photovoltaic system has the array of cells consists of PV material in which solar radiation converts to DC and further DC is converted into the alternating current via inverter then it is connected to utilitygrid. Maximum power obtained from Solar Photovoltaic system directly proportional to solar irradiance intensity. Wind turbine operates like a prime mover coupled to DC generator. A Pulse Width Modulation (PWM) technique converts output of DC generator to 3- $\Phi \mathrm{AC}$ voltage. Whenever rotor blades strike the wind, wind turbine extracts maximum K.E from the wind. PWM is used to obtain 3- $\Phi$ AC voltage from the output of DC generator.

A $60 \mathrm{~km}$ length transmission network is considered in between Bus1 and Bus2 as test case in this paper. At $10 \mathrm{~km}$ distance of transmission network at bus 3 formulated with wind energy source of capacity 9MVA, $575 \mathrm{~V}$ through a transformer of $575 \mathrm{~V} / 25 \mathrm{KV}$ is connected. A bus 4 formulated with battery, Solar Photovoltaic and Fuel cell energy source of capacity 400KVA connected through transformer of $575 \mathrm{~V} / 25 \mathrm{KV}$. Using the power system block set (PSB) and the SIMULINK software, the test system is simulated. The test system single line diagram is shown in Figure 1 and model simulation diagram as described in Figure 2.

The complete algorithm of the proposed scheme is provided below:

Step 1: Determination of the phase currents

Step 2: Calculation of detailed-coefficients and sum of detailed-coefficients

Step 3: Comparison of sum of detailed-coefficients with the threshold value

Step 4: Identification of fault on the terminals

Step 5: Classification of the fault type at the terminal by comparing with threshold value

The 3- $\Phi$ currents of the local terminal are analyzed with Mother Biorthogonal 1.5 wavelet to obtain the detailed-coefficients over a $1 / 2$ cycle length moving window. The detailed-coefficients are calculated from the Bus1, Bus 2, Bus3 and Bus4 to obtain effective D1 coefficients. The each phase Fault Index is then calculated.

The results are plotted for different faults are given below. The location of fault in the system can be observed by comparing variation of measured current index at all buses. Figure 3 shows that the Double line to ground (LLG) faul at terminall. Phase A to ground fault (LG) at terminallwith a FIA $0^{0}$ which is illustrated in Figure 4. Sum of detailed-coefficients of phase currents shown in Figure 5 and observed that LG fault. All the faulty phase index values are above threshold values can be identified type of the fault shoes that the LG fault at FIA $20^{\circ}$ as shown in Figure 6, the LLG fault at FIA $40^{\circ}$ as illustrated in Figure 7, the LL fault at FIA $20^{\circ}$ as shown in Figure 8 and 3- $\Phi$ fault at FIA2 $0^{\circ}$ as shown in Figure 9 Figures 6-9. shows that the fault index variation for transmission system LG, LL, LLG fault at FIA $40^{\circ}$ from terminall. 


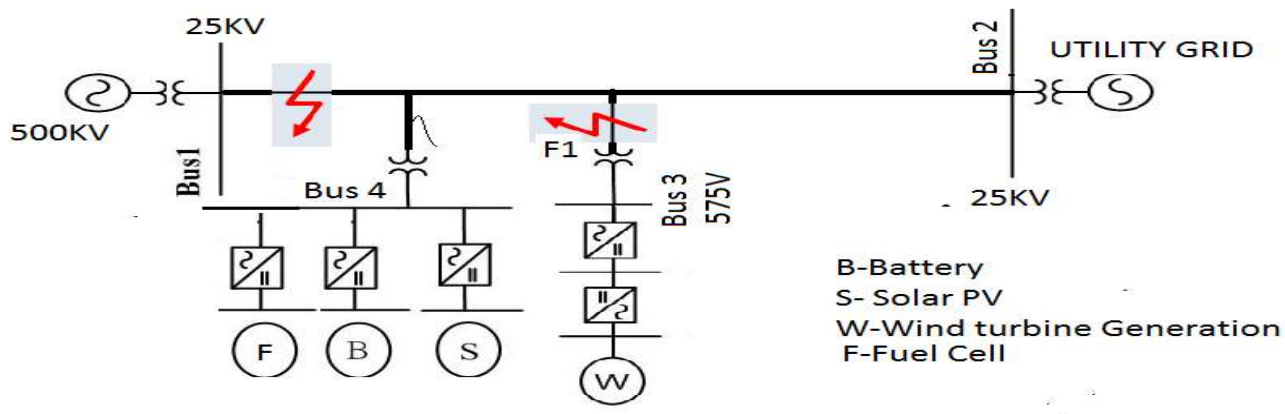

Figure 1. Single line diagram for micro-grid connected to utility grid

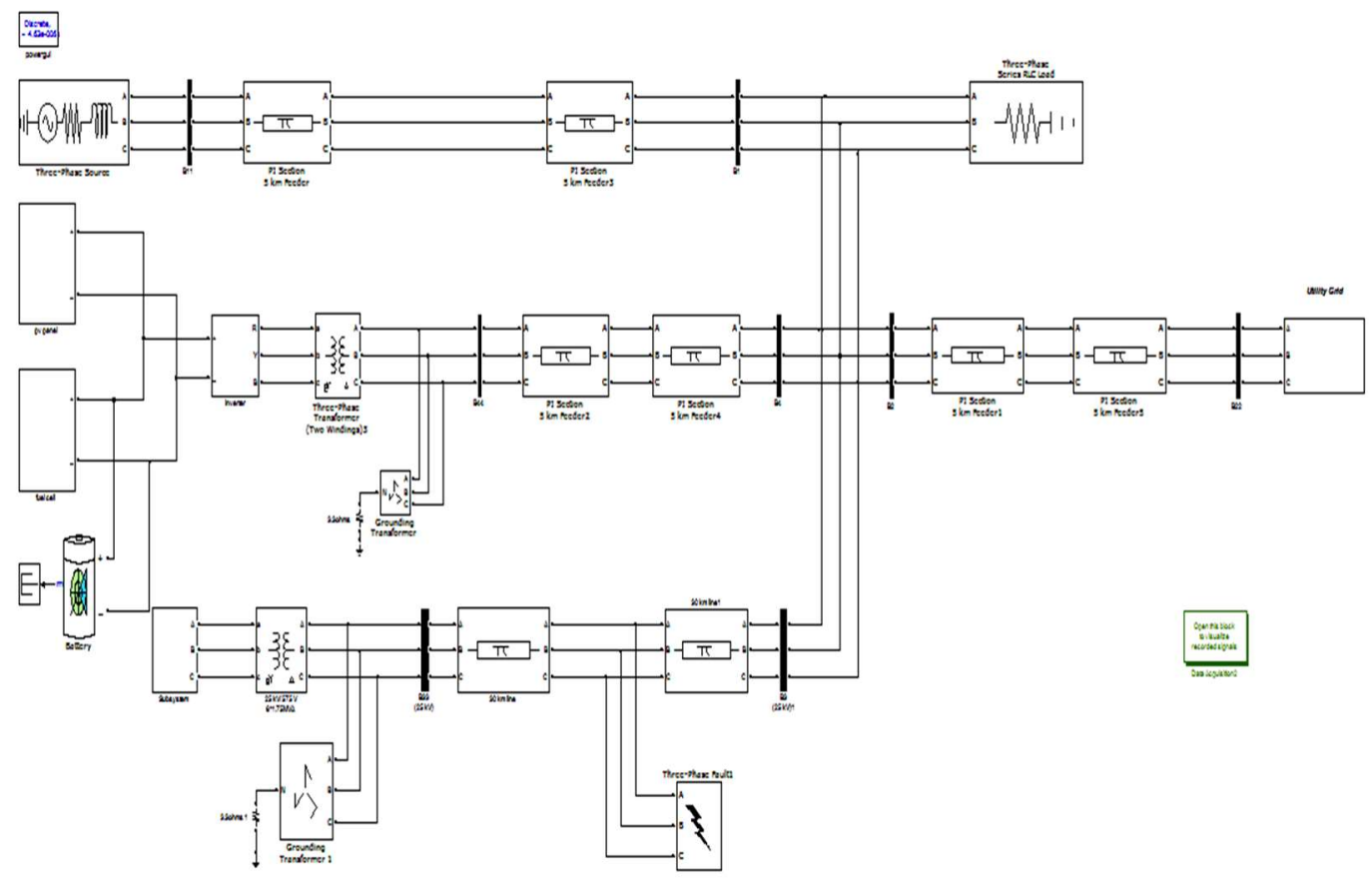

Figure 2. Simulation model for proposed system
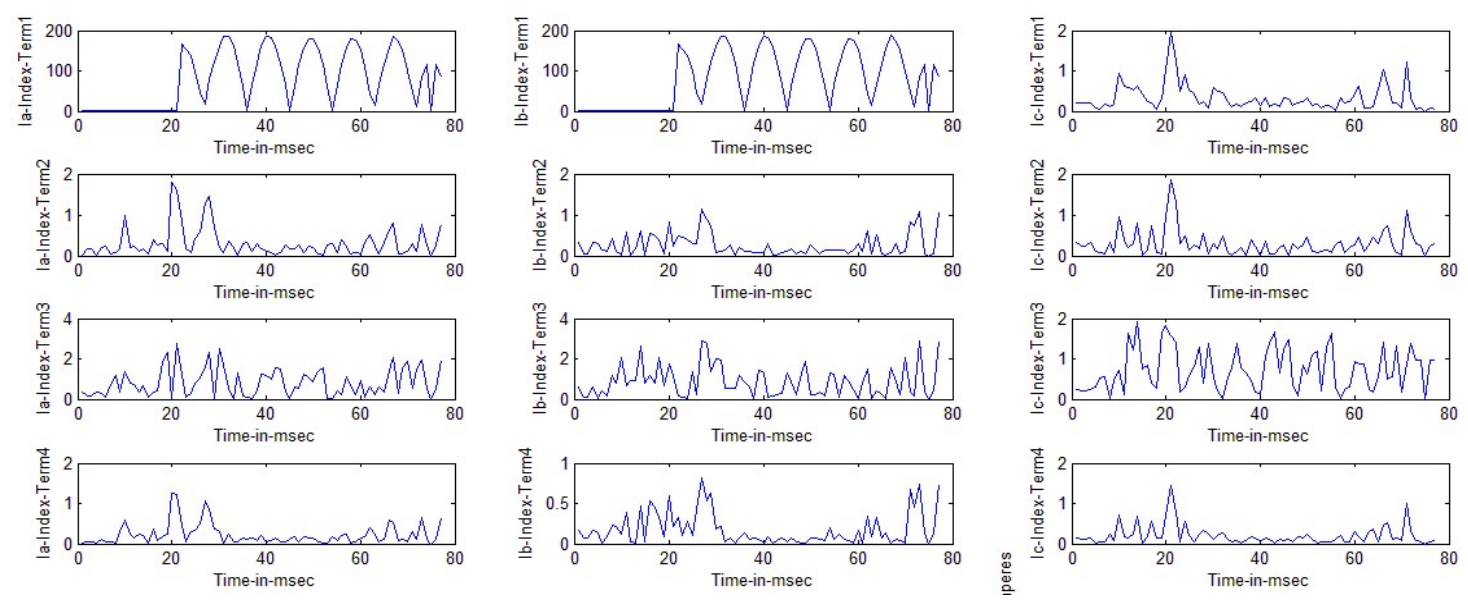

Figure 3. Fault index variation of all phase currents at Bus1 to Bus 4 to detect fault terminal 


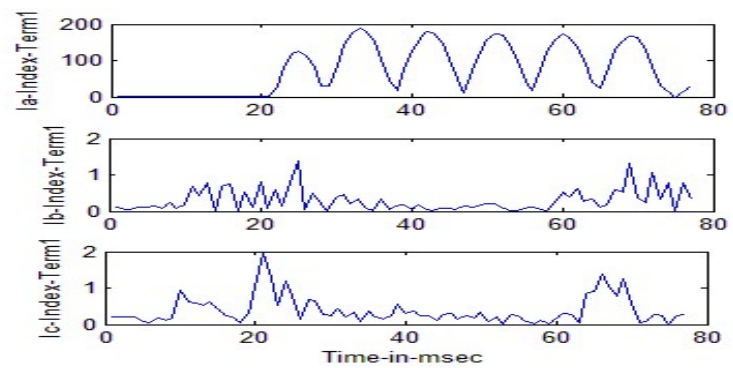

Figure 4. Fault index variation of all phase currents at terminal1 at LG Fault on phase A

FIA 20

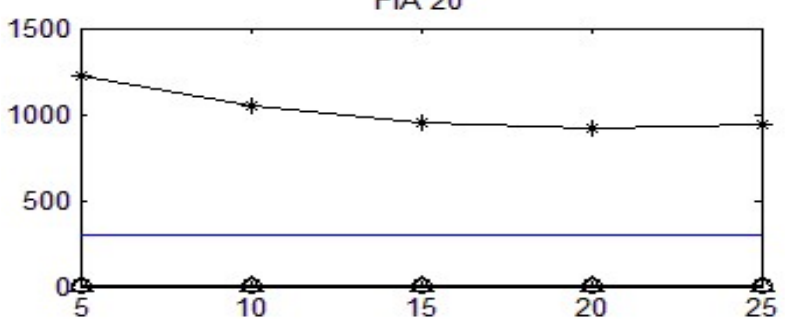

Figure 6. Fault index variation from terminallunder LG fault at FIA20 ${ }^{\circ}$

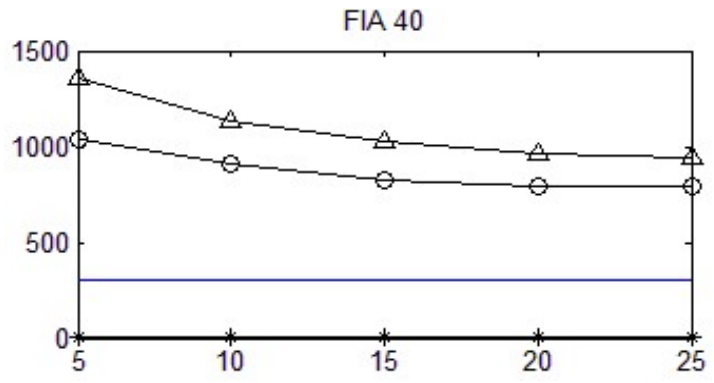

Figure 8. Fault index variation from terminal1 under LLG fault at FIA40

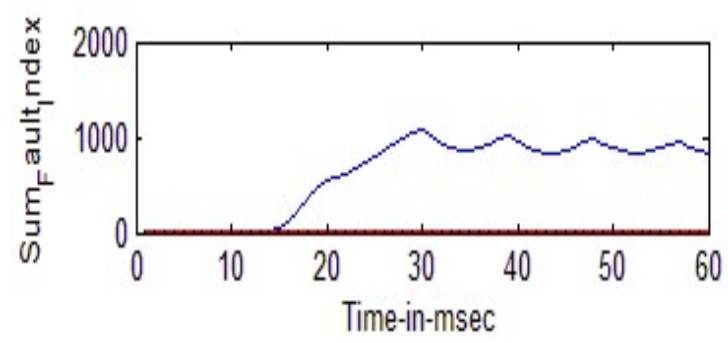

Figure 5. Variation of sum of detailed-coefficients phases currents at terminall at LG Fault on phase

A

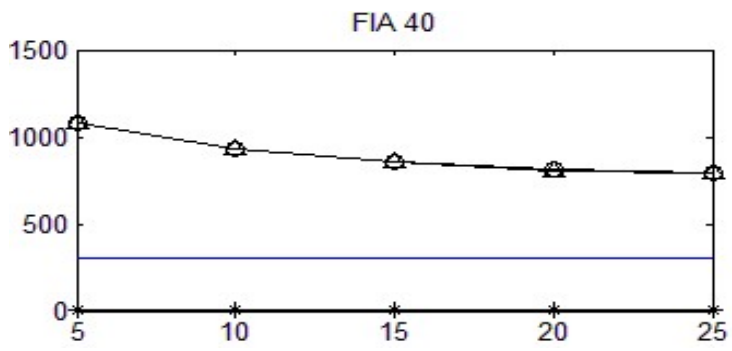

Figure 7. Fault index variation from terminal1 under LL fault at FIA $40^{\circ}$

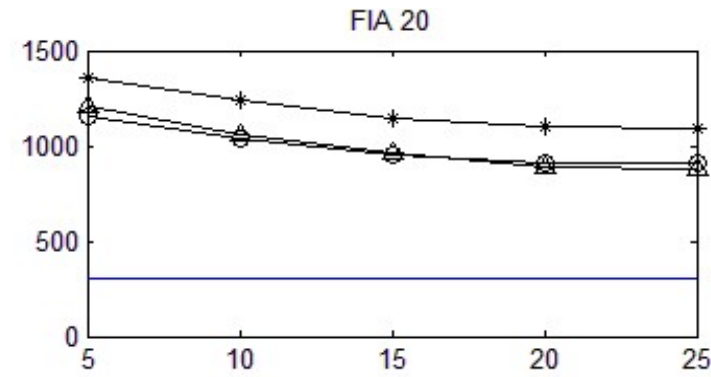

Figure 9. Fault index variation from terminall under LLLG fault at FIA20 ${ }^{\circ}$

Phase A\&B to ground fault (LLG) at terminal2 which is illustrated in Figure 10. Sum of detailedcoefficients of phase currents shown in Figure 11 and observed that LLG fault.To identify the type of fault, phases index values are above threshold values, it can be identified that the type of fault. Figure 12 shows LG fault on terminal2, the LLG fault on terminal2 as illustrated in Figure 13 the LL fault on terminal2 as shown in Figure 14 and 3- $\Phi$ fault on terminal2 as shown in Figure 15. Figures 12-15 shows that the variation of fault index for transmission system LG, LL and LLG fault at various FIA's from terminal2. 

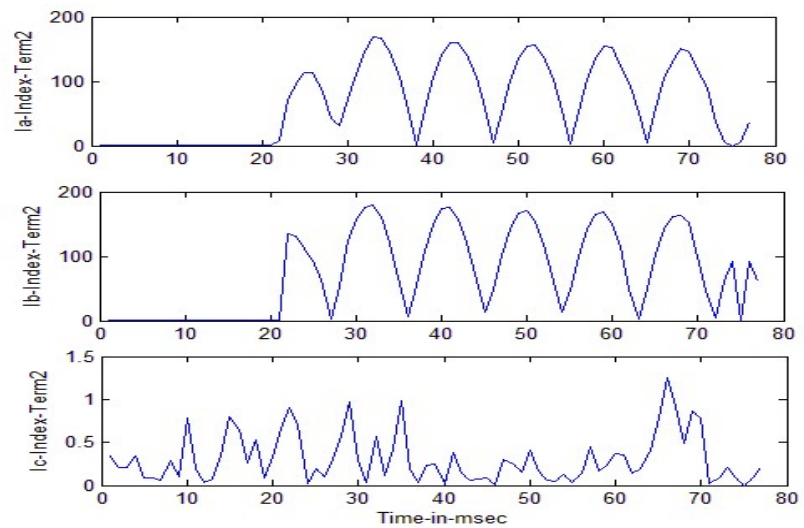

Figure 10. Fault index variation of all phase currents at terminal2 at LLG Fault on A and B phase

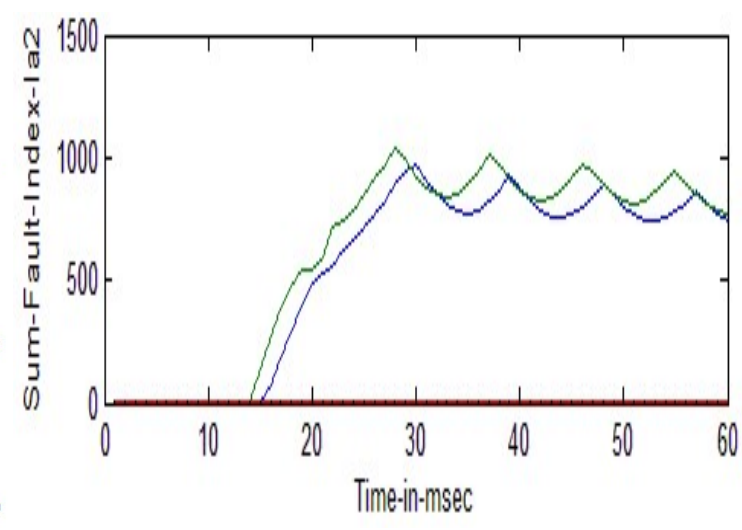

Figure 11. Variation of sum of detailedcoefficients phases currents at terminal2 at LLG Fault on A and B phase

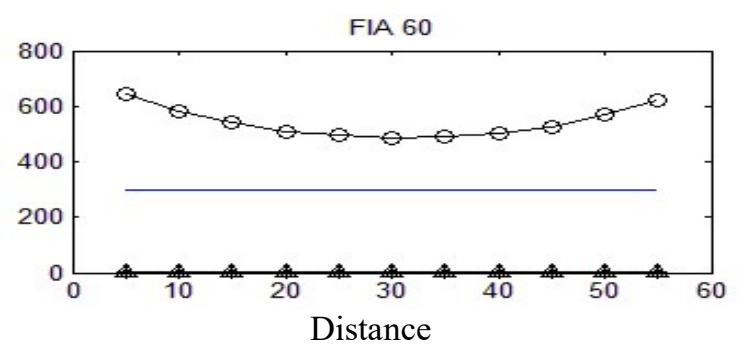

Figure 12. Fault index variation from terminal2 under LG Fault at FIA60 ${ }^{0}$

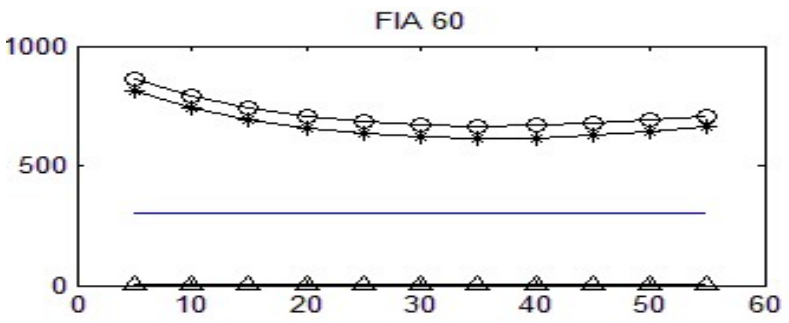

Figure 14. Fault index variation from terminal2 under LLG fault at FIA $40^{\circ}$

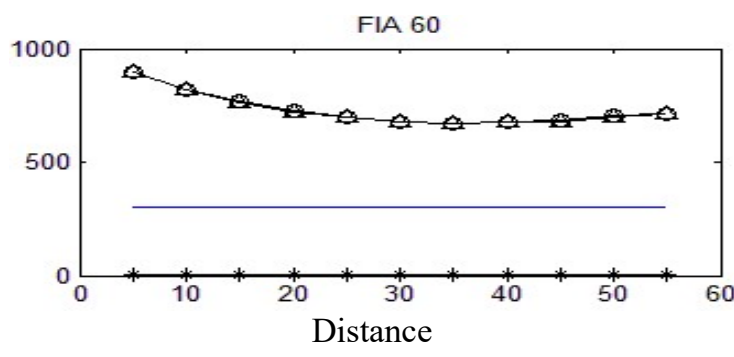

Figure 13. Fault index variation from terminal2 under LLG at FIA60 ${ }^{\circ}$

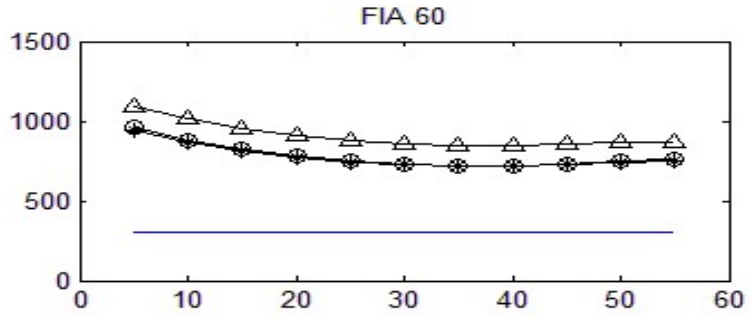

Figure 15. Fault index variation from terminal 2 under LLLG fault at FIA20 ${ }^{\circ}$

Phase A\&B fault (LL) at terminal3 which is illustrated in Figure 16. Sum of detailed-coefficients of phase currents shown in Figure 17 and observed that LL fault. To identify the type of fault, phases index values are above threshold values, it can be identified that the type of fault. Figure 18 shows LG fault on terminal3, the LLG fault on terminal3 as illustrated in Figure 19, the LL fault on terminal3 as shown in Figure 20 and 3- $\Phi$ fault on terminal3 as shown in Figure 15. Figures 18-20 shows that the variation of fault index for transmission system LG, LL and LLG fault at various FIA's from terminal3.

Phase B\&C to ground fault on terminal4 which is illustrated in Figure 21, Figure 22 shows LG fault on terminal4, the LLG fault on terminal4 as illustrated in Figure 23, the LL fault on terminal4 as shown in Figure 24 and 3- $\Phi$ fault on terminal4 as shown in Figure 15. Figures 22-25 shows Fault index variation for transmission system LG, LL and LLG fault at various FIA's from terminal4. 


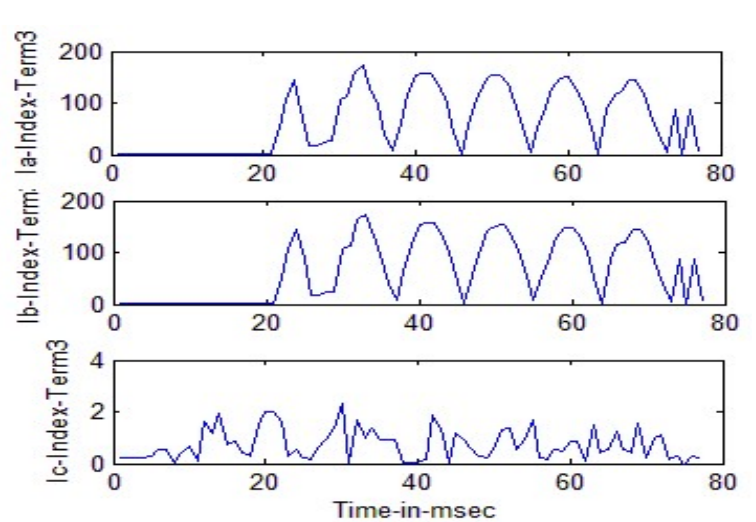

Figure 16. Fault index variation of all phase currents at terminal3 at LL Fault on A and B phase

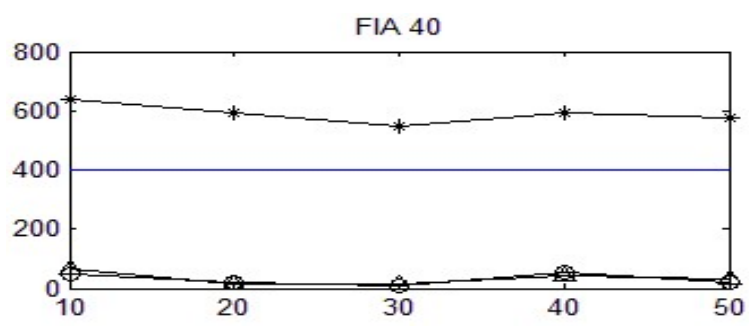

Figure 18. Fault index variation from terminal3 under LG fault at FIA $40^{\circ}$

FIA 40

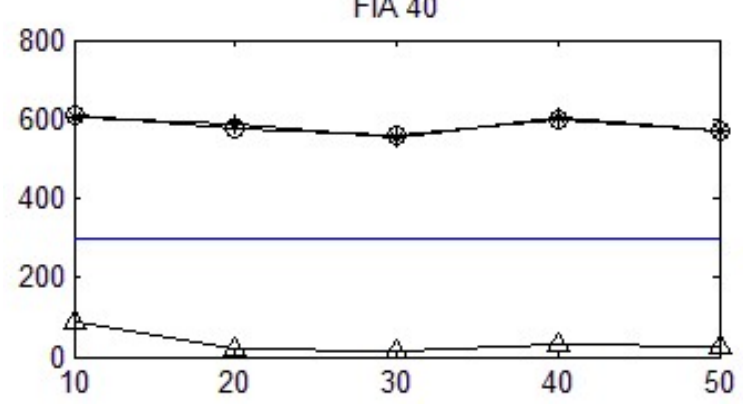

Figure 20. Fault index variation from terminal2 under LL fault at FIA40

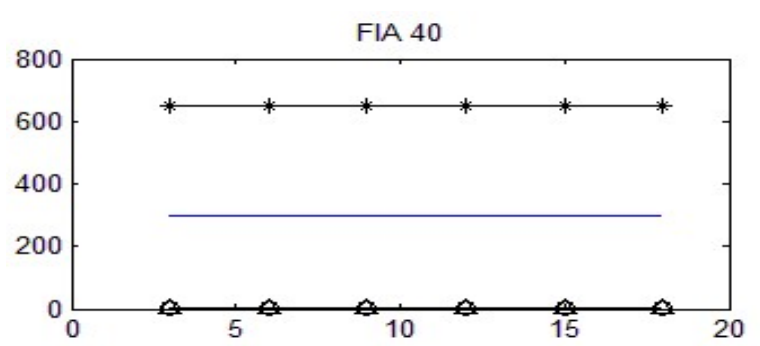

Figure 22. Fault index variation from terminal4under LG fault at FIA40 ${ }^{\circ}$

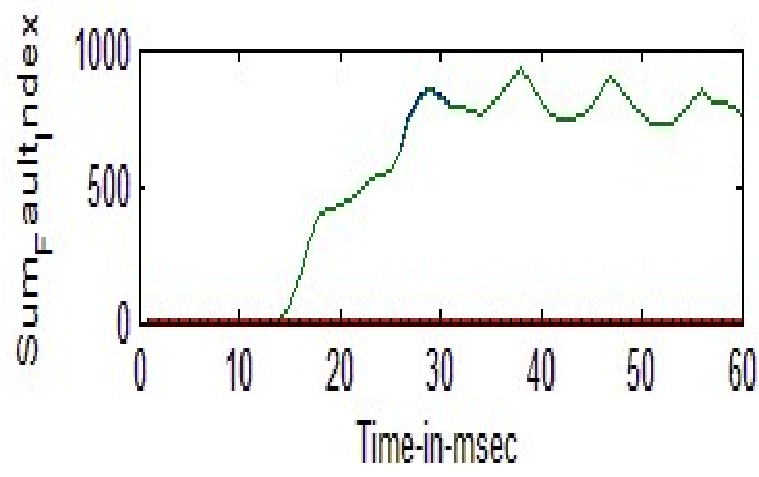

Figure 17. Variation of sum of detailed-coefficients phase currents at terminal2 at LL Fault on A and

B phase

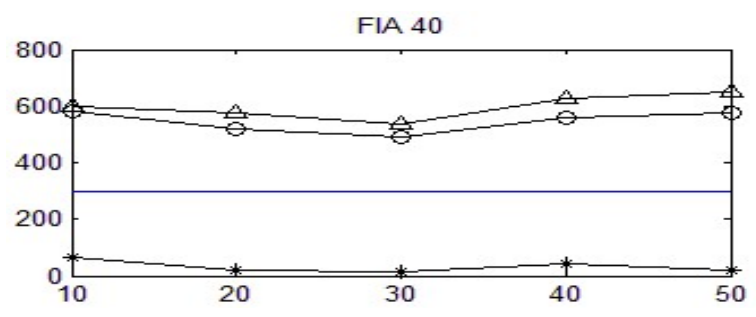

Figure 19. Fault index variation from terminal3 under LLG fault at FIA $40^{\circ}$

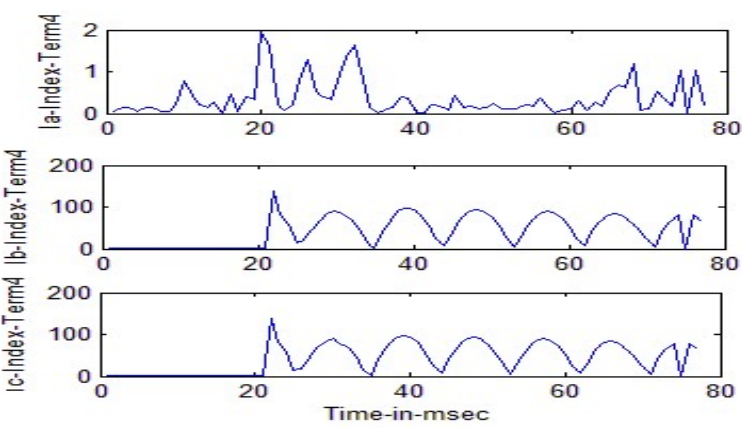

Figure 21. Fault index variation of all phase currents at terminal4 at LL Fault on A and B phase

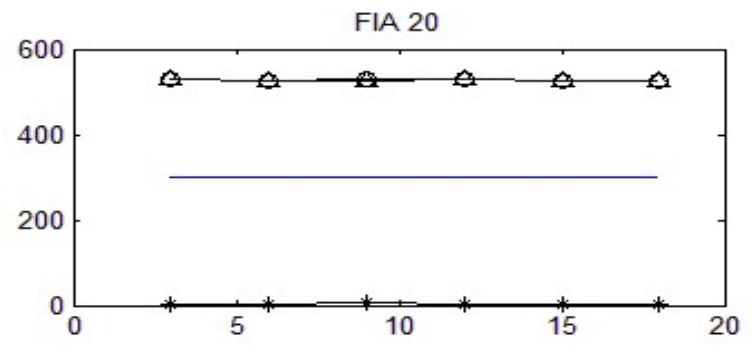

Figure 23. Fault index variation from terminal4 under LL fault at FIA $20^{\circ}$ 


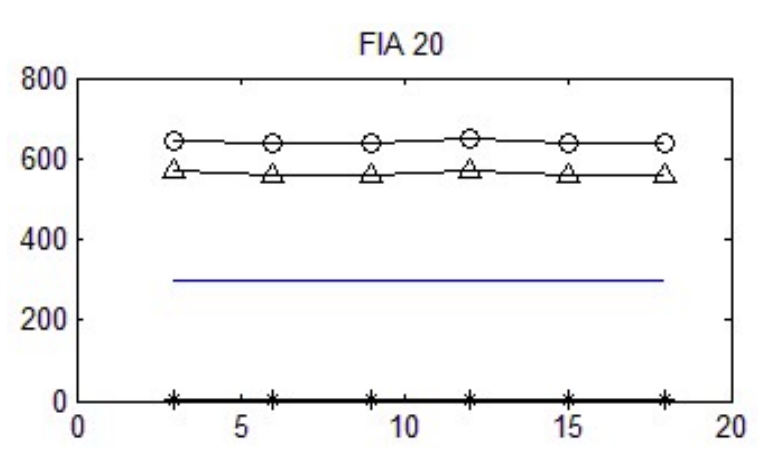

Figure 24. Fault index variation from terminal4 under LLG fault at FIA20 ${ }^{\circ}$

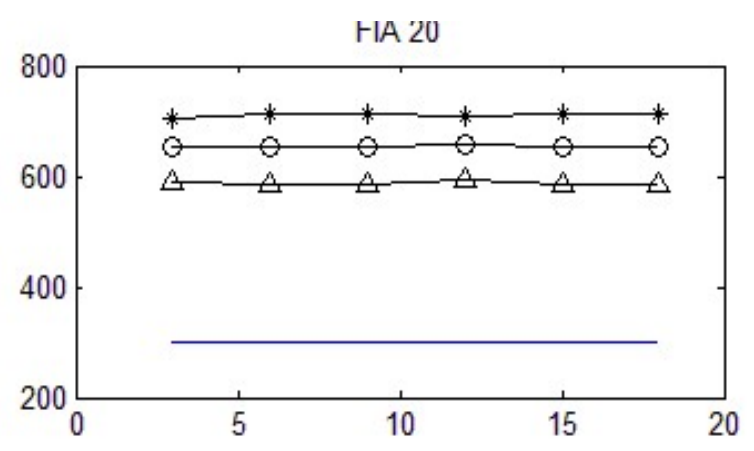

Figure 25. Fault index variation from terminal 4 under LLLG fault at FIA20 ${ }^{\circ}$

\section{CONCLUSIONS}

The protection scheme must ensure that safe operation of the micro-grid in both modes of operation, i.e the grid connected mode and island mode. Due to contribution of host grid in grid connected mode fault currents are large and Micro-grids comprise Distributed Energy Resources (DER's) with LVdistribution systems having controllable loads which can operate with different voltage levels are connected to the microgrid and operated in grid mode or islanding mode in a coordinated way of control.The provision of properly reliable and coordinated protection scheme can reliably trip in the event of a fault within it. In this paper, the test system is created and simulated using the power system block set with SIMULINK software. Wavelet based Multi-resolution Analysis is used for detection, discrimination and location of faults on transmission network. D1 detail-coefficients of current signals using Mother Biorthogonal 1.5 wavelets are used to detection, discrimination and location of fault. The proposed protection scheme is found to be fast, reliable and accurate for various types of faults on transmission network with micro-grid containing fuel cell, wind turbine, solar photovoltaic and battery generation system.

\section{REFERENCES}

[1] D. Ming, et al., "Key Technologies for Microgrids a Review", in Sustainable Power Generation and Supply, 2009. SUPERGEN '09. International Conference on, pp. 1-5, 2009.

[2] Oudalova and A. Fidigattibfd, “Adaptive Network Protection in MICROGRID," 2011. www.microgrids.eu/documents/519.pdf.

[3] N. Chaitanya, P. Sujatha, K. Chandra Sekhar "Current Controller Based Power Management Strategy for Interfacing DG Units to Micro Grid” International Journal of Electrical and Computer Engineering, Vol. 7, No. 5, pp. 2300 2308, October 2017.

[4] H. Nikkhajoei and R. H. Lasseter, “Microgrid Protection,” IEEE PES General Meeting, Tampa, pp. 1-6, 24-28 June 2007.

[5] A. Oudalov, et al., "Novel Protection Systems for Microgrids", 2009.

[6] A. S. Oshaba and E. S. Ali, "Bacteria Foraging: A New Technique for Speed Control of DC Series Motor Supplied by Photovoltaic System", International Journal of WSEAS Transactions on Power Systems, Vol. 9, pp. 185-195, 2014.

[7] X.-P. Wang, Y. Li and Y.-Y. Yu, "Research on the Relay Protection System for a Small Laboratory Scale Microgrid System," Proceedings of the 6th IEEE Conference on Industrial Electronics and Applications, Beijing, pp. 2712-2716, 21-23 June 2011.

[8] S. Ustun, C. Ozansoy and A. Zayegh, "A Microgrid Protection System with Central Protection Unit and Exensive Communication," Proceedings of the 10th International Conference on Environment and Electrical Engineering, Rome, pp. 1-4, 8-11 May 2011.

[9] T. B. Littler and d. J. Morrow. "Wavelets for the Analysis and Compression of Power System Disturbances", IEEE Transactions on Power Delivery, vol. 14, pp. 358-364, Apr. 1999.

[10] Kulkarnisakekar Sumant Sudhir, "Wavelet Based Fault Detection \& ANN Based Fault Classification In Transmission Line Protection Scheme”, International Journal of Engineering Research \& Technology, Vol. 2 Issue 5, pp. 1492-1500, May-2013.

[11] S.G.Mallat, "A Theory for Multi Resolution Signal Decomposition: The Wavelet Representation", IEEE Trans. Pattern Anal. Machine Intell, vol.11, pp.674-693, July 1989.

[12] P.Makming,S.Bunjongjit, A.Kunakorn,S.Jiriwibhakorn, M.Kando, "Fault Diagnosis in Transmission Lines Using Wavelet Transform Analysis", IEEE/PES Transmission and Distribution Conference and Exhibition 
[13] RicardoEscudero JulienNoel JorgeElizondo JamesKirtley "Microgrid fault detection based on wavelet transformation and Park's vector approach" Electric Power Systems Research, Volume 152, Pages 401-410, November 2017.

[14] K. M. Priyadharshini, S. Srinivasan, C. Srinivasan "Detection of Power Quality Disturbances in Micro Grid Connected Power System”, TELKOMNIKA Indonesian Journal of Electrical Engineering, Vol. 14, No. 1, pp. 9-15, April 2015.

[15] Omar Mohammed Benaissa, Samir Hadjeri, Sid Ahmed Zidi, "Modeling and Simulation of Grid Connected PV GenerationSystem Using Matlab/Simulink”, International Journal of Power Electronics and Drive System, Vol. 8, No. 1, pp. 392 401, March 2017. 